\title{
Optimization of Rhodamine B Decolorization by Adsorption and Photoelectrodegradation Combination System
}

\author{
Sayekti Wahyuningsih ${ }^{a^{*}}$, Velina Anjani ${ }^{a}$, Hanik Munawaroh ${ }^{\mathrm{b}}$ and Candra Purnawan $^{a}$ \\ ${ }^{a}$ Department of Chemistry, Faculty of Mathematics and Natural Sciences, University of March, Jl. Ir. Sutami \\ 36A Kentingan Surakarta 57126, Indonesia \\ ${ }^{b}$ Chemistry Department of Graduate Program, Sebelas Maret University, Jl. Ir. Sutami 36A Kentingan \\ Jebres Surakarta 57126, Indonesia \\ * Corresponding author \\ E-mail: sayekti@mipa.uns.ac.id
}

DOI: 10.20961/alchemy.14.2.16440.277-290

Received 29 November 2017, Accepted 10 August 2018, Published Online 03 September 2018

\begin{abstract}
A combination of adsorption and photoelectrodegradation system was performed to reduce the concentration of Rhodamine B dye in water. The adsorption was conducted using silica and alumina activated by acid and base under various predetermined $\mathrm{pH}$ of Rhodamine $\mathrm{B}$. The photoelectrodegradation process was performed using $\mathrm{Ti} / \mathrm{TiO}_{2}$ electrode as a cathode and $\mathrm{Ti} / \mathrm{TiO}_{2}-\mathrm{NiO}$ as an anode. $\mathrm{TiO}_{2}$ was synthesized from titanium tetra-isopropoxide precursor (TTiP) by sol-gel method. $\mathrm{TiO}_{2}-\mathrm{NiO}$ composite was synthesized with the same precursor with the addition of $\mathrm{Ni}\left(\mathrm{NO}_{3}\right)_{2} \cdot 6 \mathrm{H}_{2} \mathrm{O}$. The result shows that the activation changes the amount of $\mathrm{OH}$ total in the adsorbent. The acid-activated adsorbent showed an optimum adsorption activity when Rhodamine B was in base condition caused by zwitter ionic structure. It reversely occured to base-activated adsorbent where an optimum absorption activity reached at acid condition. The application of base-activated silica in adsorption and photoelectrodegradation combination system decreased the concentration of Rhodamine $\mathrm{B}$ dye up to $98.79 \%$ using photoanode $\mathrm{Ti} / \mathrm{TiO}_{2}-\mathrm{NiO}$ under $\mathrm{pH} 2$ at bias potential $6 \mathrm{~V}$.
\end{abstract}

Keywords: adsorption, photoelectrodegradation, Rhodamine $\mathrm{B}, \mathrm{TiO}_{2}-\mathrm{NiO}$

\section{INTRODUCTION}

The waste textile industry is generally derived from the coloring process using azo dyes group containing chromophore (Sen and Demirer, 2003) which is non-biodegradable that cannot be decomposed by heat and bacteria. One of the textile components are often used as a dye is Rhodamine B. Various waste treatment techniques such as filtration, coagulation, sedimentation, ion exchange and adsorption have been carried out. The adsorption method is considered an effective method of waste treatment and the process is fast. Some adsorbent that often used in adsorption are silica and alumina due to the high efficiency because of the surface area, porosity, and high mechanical properties and has good resistivity to thermal degradation (Malakootian et al., 2015). Silica has active Si-OH groups 
called silanol and known to be effective adsorption agent when it is applied as an adsorbent as well as alumina that have $\mathrm{O}-\mathrm{H}$ group. Therefore, silica and alumina can be used as an adsorbent in the adsorption of the dye Rhodamine B (Kannan et al., 2008; Huang et al., 2011; Alver et al., 2012; Sun et al., 2013).

The adsorption process is less optimal for dealing with the waste dye because it is merely quarantining adsorbed molecules and their interaction is limited to physical interactions. Research on the photodegradation by sunlight using $\mathrm{TiO}_{2}$ catalyst shows that $\mathrm{TiO}_{2}$ can degrade and eliminate the compound of methylene blue dye and produce the final product in the form of $\mathrm{CO}_{2}, \mathrm{SO}_{4}{ }^{2-}, \mathrm{NH}_{4}^{-}$, and $\mathrm{NO}_{3}{ }^{-}$(Gunlazuardi, 2001). Thus, sewage treatment of Rhodamine B dye using adsorption combined with photoelectrocatalytic degradation can transform waste into a mineral dye that is more environmentally friendly.

Titanium metal oxides reported as a semiconductor material with a higher photocatalytic activity, more stable, and non-toxic. In addition to these activities, the $\mathrm{TiO}_{2}$ powder is obtained and produced in large quantities. However, $\mathrm{TiO}_{2}$ has a high energy gap that is proportional to the light of $388 \mathrm{~nm}(3.23 \mathrm{eV})$, where the ultraviolet light with this amount energy is only available at $10 \%$ of the sunlight. This limitation can be overcome by modification of $\mathrm{TiO}_{2}$ by doping it with metal ions and other oxides as well as photosensitizing such various organic and inorganic colored compounds.

One way to overcome these weaknesses is by adding a metal oxide $\mathrm{NiO}$ with lower bandgap energy to enhanced the photocatalytic activity of $\mathrm{TiO}_{2}$ (Wahyuningsih et al., 2014) and can extend the photo-response of $\mathrm{TiO}_{2}$ to the area visible to be used for the degradation of organic contaminants colored and organic pollutants other (Lisenbigler et al., 1995). Additionally, an electrical potential can be added to mitigate these weaknesses and to improve $\mathrm{TiO}_{2}$ activation and degradation of organic compounds. The transfer of electrons and electrical current is expected to increase the activation of $\mathrm{TiO}_{2}$ and the degradation of organic compounds, especially dye of Rhodamine B.

The structure of the Rhodamine B is a cationic compound and can form different structures under different $\mathrm{pH}$ conditions (Jain et al., 2007), wherein low $\mathrm{pH}(\leq 5)$ Rhodamine $\mathrm{B}$ forms a cationic structure, and at high $\mathrm{pH}(\geq 6)$ Rhodamine $\mathrm{B}$ forms the zwitter ion structure (Motahari et al., 2014) which will affect the adsorption and photoelectrocatalytic activity. Therefore, $\mathrm{pH}$ variation of Rhodamine $\mathrm{B}$ was studied to determine the optimum $\mathrm{pH}$ condition of the solution.

The present study explores the optimization of Rhodamine B decolorization using a combination of adsorption and photoelectrocatalytic system. Using the combination of this 
system, the degradation of Rhodamine B increased thus its application in the wastewater treatment will reduce the environmental pollution.

\section{EXPERIMENTAL SECTION}

Materials were used are titanium tetra-isopropoxide (TTiP) from Aldrich, Ti plate (3 cm x $10 \mathrm{~cm}$ ) of Baoji Titanium Qixin Co.Ltd, silica, alumina, Rhodamine B dye, ethanol, acetic acid, nickel nitrate, polyvinyl alcohol (PVA), hydrochloric acid and sodium hydroxide were purchased from E. Merck (Indonesia). All reagents were analytical reagent grade quality. All solutions were prepared with double distilled water.

\section{Adsorbents activation}

Activation process has been done by mixing each silica $(50 \mathrm{~g})$ and alumina (50 g) into $\mathrm{H}_{2} \mathrm{SO}_{4} 1 \mathrm{M}(250 \mathrm{~mL})$ and $\mathrm{NaOH} 1 \mathrm{M}(250 \mathrm{~mL})$ for an hour. A mixed solution of adsorbent in acid or base washed by water until a neutral solution obtained. Each adsorbent was analyzed by FTIR Shimadzu model $8201 \mathrm{PC}$ (ratio mass of sample: $\mathrm{KBr}=1: 200$ ).

\section{Adsorption Process}

The optimum conditions of the adsorbent can be determined by adsorption process of Rhodamine B solution (10 ppm, $12.5 \mathrm{~mL})$ using silica $(0.5 \mathrm{~g})$ and alumina $(0.5 \mathrm{~g})$ with various treatment such as without activation process, acid activated, and base activated on shaker rotary for 60 minutes. The filtered mixed solutions were then analyzed by Lambda 25 Perkin Elmer UV-Vis spectrophotometer.

The adsorption process of Rhodamine B $10 \mathrm{ppm}(12.5 \mathrm{~mL})$ at various $\mathrm{pH}$ condition i.e. $2,3,4,5,6,7,8,9,10,11$, and 12 , was performed with addition of silica $(0.5 \mathrm{~g})$ and alumina $(0.5 \mathrm{~g})$ activated by acid and base and was shaken for 60 minutes. The filtered mixed solutions were then analyzed by Lambda 25 Perkin Elmer UV-Vis spectrophotometer. The percentage adsorbed (\%) of Rhodamine B can be calculated using equation 1.

$$
\% \text { adsorption }=\frac{C o-C r}{10} \times 100 \%
$$

where $\mathrm{C}_{0}$ : Initial concentration; $\mathrm{Cr}$ : Concentration of residual adsorption

\section{Synthesis and preparation of $\mathrm{Ti} / \mathrm{TiO}_{2}$ electrode}

The $\mathrm{TiO}_{2}$ film was synthesized using procedures published previously (Wahyuningsih et al., 2014). $10 \mathrm{~mL}$ solution of TTiP was hydrolyzed in $100 \mathrm{~mL}$ acetic acid glacial solution and mixed under vigorous stirring in an ice waterbath $\left(10^{\circ} \mathrm{C}-15^{\circ} \mathrm{C}\right)$ until a clear yellow solution of $\mathrm{TiO}_{2}$ was formed. The solution was heated at $90{ }^{\circ} \mathrm{C}$ for $2 \mathrm{~h}$ until it became a gel, which was then placed in an oven at $150{ }^{\circ} \mathrm{C}$ for $24 \mathrm{~h}$ to undergo an aging 
process. Next, the $\mathrm{TiO}_{2}$ xerogel was calcinated in a muffle furnace at $400{ }^{\circ} \mathrm{C}$ for $2 \mathrm{~h}$ at a heating rate of $10^{\circ} \mathrm{C} \cdot \mathrm{min}^{-1}$. The $\mathrm{TiO}_{2}$ powder (12.5 grams) and 1 grams of PVA was added into $50 \mathrm{~mL}$ of ethanol and stirred for $15 \mathrm{~min}$. Then $\mathrm{TiO}_{2}$ solution was sprayed to Ti plate. The $\mathrm{TiO}_{2}$-coated $\mathrm{Ti}$ plate was then dried at $200{ }^{\circ} \mathrm{C}$ for $15 \mathrm{~min}$. The coating and drying treatments were repeated until Ti plate covered completely. Materials were characterized by XRD (Bruker D8 Advance).

\section{Synthesis and preparation of $\mathrm{Ti} / \mathrm{TiO}_{2}-\mathrm{NiO}$ electrode}

The $\mathrm{TiO}_{2}-\mathrm{NiO}$ composite was synthesized using a procedure published previously (Wahyuningsih et al., 2014). 1.145 grams of synthesized xerogel $\mathrm{TiO}_{2}$ (previous procedure) was added in 0.81 grams of $\mathrm{NiNO}_{3} \cdot 6 \mathrm{H}_{2} \mathrm{O}$ that has dissolved in $25 \mathrm{~mL}$ of distilled water. The mixed solution was stirred with a magnetic stirrer to fuse. Then, the uniform mixture was dried at $110^{\circ} \mathrm{C}$ for $3 \mathrm{~h}$. To improve the crystalline $\mathrm{TiO}_{2}-\mathrm{NiO}$ after the green suspension was formed, it was calcinated at $700{ }^{\circ} \mathrm{C}$ for $4 \mathrm{~h}$ at $10{ }^{\circ} \mathrm{Cmin}^{-1}$. The crystalline $\mathrm{TiO}_{2}-\mathrm{NiO}(12.5$ grams) and 1 gram PVA was added into $50 \mathrm{~mL}$ of ethanol and stirred for $15 \mathrm{~min}$. The $\mathrm{TiO}_{2}-$ $\mathrm{NiO}$ solution was sprayed to Ti plate and dried at $200{ }^{\circ} \mathrm{C}$ for $15 \mathrm{~min}$. The coating and drying treatments were repeated until Ti plate covered completely. Materials were characterized by XRD (Bruker D8 Advance).

\section{Photoelectrocatalytic (PEC) Degradation Process}

PEC degradation process of Rhodamine B 10 ppm solution at optimum $\mathrm{pH}$ (from adsorption process) was performed by a batch method using $\mathrm{Ti} / \mathrm{TiO}_{2}$ as a cathode and $\mathrm{Ti} / \mathrm{TiO}_{2}-\mathrm{NiO}$ as an anode. The PEC degradation process was performed at voltages of $6 \mathrm{~V}$ from DC Power Supply (ATTEN TPR3005T-3C) under visible light irradiation from a 300 Watt halogen lamp (Osram $300 \mathrm{Watt}$ ) for $10 \mathrm{~min}$. The degradation process was done in a closed black box. Rhodamine B solution after degradation was analyzed by Lambda 25 Perkin Elmer UV-Vis spectrophotometer. The percentage degradation (\%) of Rhodamine B was calculated using equation 2.

$$
\% \text { degradation }=\frac{C o-C r}{10} \times 100 \%
$$

where $\mathrm{C}_{0}$ : Initial concentration; $\mathrm{Cr}$ : Concentration of residual degradation

Residual concentration of Rhodamine B after adsorption and degradation was calculated with equation (5). In which A is the residual Rhodamine B after adsorption (equation (3)), and $\mathrm{B}$ is the residual Rhodamine $\mathrm{B}$ after degradation (equation (4)). The decreasing of Rhodamine B concentration after treatment was calculated with equation (6).

$\mathrm{Cr}($ residual adsorption $)=\mathrm{A}$ 
$\mathrm{Cr}$ (residual adsorption) $\mathrm{x}(\%$ degradation $/ 100)=\mathrm{B}$

$\%$ degradation and adsorption $(\mathrm{C})=C o-\frac{A-B}{10} \times 100 \%$

$\%$ decreasing activity $=(\mathrm{C}-\%$ degradation $)$

\section{RESULTS AND DISCUSSION}

\section{Acid and Base Activation of Adsorbents}

Activation performed on silica affects the active site of silica because the addition of the acid-base activation which the activation of the acid will enhance the acidity of the silica due to addition of the active site of $\mathrm{H}^{+}$and activation of bases will improve the properties of alkalinity in silanol $(\mathrm{Si}-\mathrm{OH})$ as the active site, silanol $(\mathrm{Si}-\mathrm{OH})$ on the surface of adsorbent undergo protonation at acid activation thus the surface positively charged. Meanwhile, the activation using a base, silanol groups on the surface of the adsorbent will lose a proton to the negatively charged surface of the adsorbent (Al-Ghouti et al., 2003).

$$
\begin{aligned}
& \mathrm{Si}-\mathrm{OH}+\mathrm{H}^{+} \rightarrow \mathrm{Si}^{-} \mathrm{OH}_{2}{ }^{+} \\
& \mathrm{Si}-\mathrm{OH} \rightarrow \mathrm{H}^{+}+\mathrm{Si}^{-} \mathrm{O}^{-}
\end{aligned}
$$

In the FTIR spectra of non-activated silica and acid-base activated, there was no significant change in the functional group. The only change occurred in the total number of $\mathrm{O}-\mathrm{H}$ due to the activation using acids and bases. FTIR spectra of the adsorbent silica nonactivated and acid-base activated can be seen in Figure 1.

The FTIR spectra of un-activated silica, acid-, and base-activated silica adsorbents show the absorption functional group of $\mathrm{O}-\mathrm{H}$ silanol group at wavenumber $3444.05 \mathrm{~cm}^{-1}$, $3462.37 \mathrm{~cm}^{-1}$, and $3441.19 \mathrm{~cm}^{-1}$, respectively. Uptake of bending vibration O-H group in silanol appears at wavenumber $1631.85 \mathrm{~cm}^{-1}$ for acid activated silica and $1632.81 \mathrm{~cm}^{-1}$ for base activated silica. The stretching vibrations asymmetry of -Si-O on siloxane appear at a wavenumber of $1095.61 \mathrm{~cm}^{-1}, 1083.08 \mathrm{~cm}^{-1}$, and $1101.40 \mathrm{~cm}^{-1}$ for un-activated, acid-, and base-activated silica adsorbents, respectively. Uptake in the area of $802.42 \mathrm{~cm}^{-1}, 801.46 \mathrm{~cm}^{-}$ ${ }^{1}$, and $795.67 \mathrm{~cm}^{-1}$ in each of the silica adsorbents showed symmetry stretching vibration of -Si-O. In the wavenumber of $975.06 \mathrm{~cm}^{-1}, 967.34 \mathrm{~cm}^{-1}$, and $954.80 \mathrm{~cm}^{-1}$ showed stretching vibration -Si-O group in silanol for each non-activated silica and acid-base activated silica. The bending vibrations from the group siloxane Si-O-Si in each of the silica adsorbents were shown by the respective absorption at wavenumber $456.18 \mathrm{~cm}^{-1}, 468.72 \mathrm{~cm}^{-1}$, and 472.58 $\mathrm{cm}^{-1}$ (Silverstein, 1991). There are differences of $\mathrm{O}-\mathrm{H}$ amount $(\Delta \mathrm{T})$ on silica adsorbents without activation, acid activated and base activated respectively $18.1 \%, 12.2 \%$, and $25.8 \%$. 
Base-activated silica contains more $\mathrm{O}-\mathrm{H}$ functional group due to silica can absorbs $\mathrm{H}_{2} \mathrm{O}$ with maximum in the base condition, so it is possible activation silica with base formed $\mathrm{Si}-\mathrm{OH}$ and $\mathrm{Si}^{-} \mathrm{O}^{\circ}$. Percentage $\Delta \mathrm{T}$ of the total content of $\mathrm{O}-\mathrm{H}$ on the higher base silica will affect silica adsorption activity with Rhodamine B.

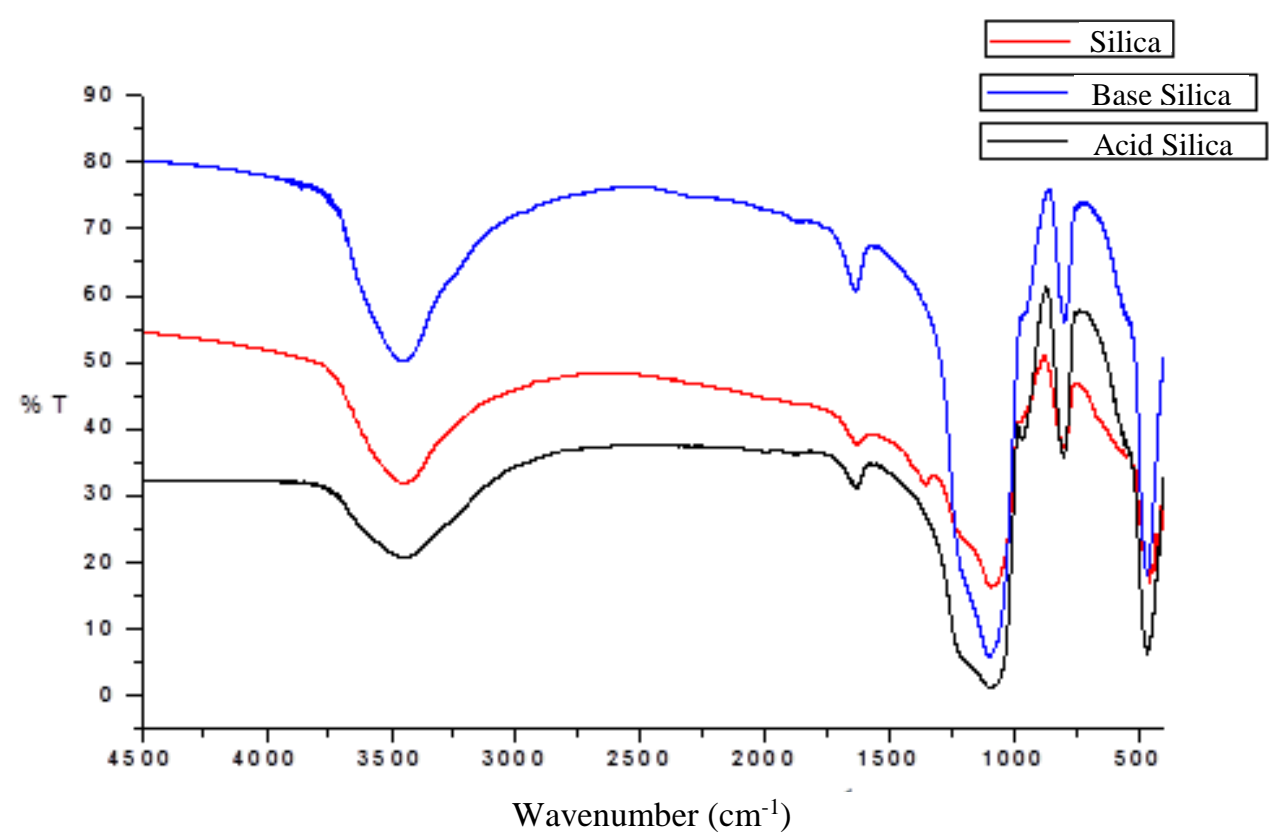

Figure 1. FTIR spectra of silica adsorbents without activation, acid activated and base activated.

Activation of alumina using acid or base caused alumina as cation and anion exchanger in accordance with conditions of activation using acid or base. The alumina had a high affinity for cationic species when it was activated using bases; whereas it has a high affinity for anionic species when it was activated using acid (Mahmoud et al., 2010). Activation using acid and base affecting active sites on the surface of alumina, which can act as Bronsted acid and base.

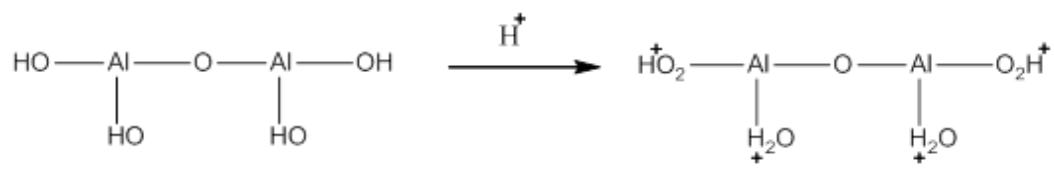

Bronsted acid<smiles>[O-]N(O[V])O[N+]([O-])[O-]</smiles>

Bronsted base

Figure 2 showed alumina FTIR spectra of non-activated alumina and acid-base activated alumina. The FTIR spectra of respective un-activated alumina, acid- and baseactivated alumina reveal $\mathrm{O}-\mathrm{H}$ stretching vibration which each appears at the wavelength of 
$3462.37 \mathrm{~cm}^{-1}, 3461.41 \mathrm{~cm}^{-1}$, and $3459.48 \mathrm{~cm}^{-1}$ and the $\mathrm{O}-\mathrm{H}$ bending vibration which each appears at the wavelength of $1630.88 \mathrm{~cm}^{-1}, 1634.74 \mathrm{~cm}^{-1}$, and $1636.67 \mathrm{~cm}^{-1}$. The vibration activated functional group Al-O of each alumina without activation, acid activation, and base activation appear at the wavelength of $775.42 \mathrm{~cm}^{-1}, 731.05 \mathrm{~cm}^{-1}$, and $732.98 \mathrm{~cm}^{-1}$. FTIR spectra results showed that no change of functional groups on the adsorbent alumina. However, the acid or base activation on alumina caused changes in the total number of $\mathrm{O}-\mathrm{H}$ active sites on alumina which affect the adsorption ability to dye Rhodamine B (Motahari et al., 2014). The $\mathrm{O}-\mathrm{H}$ content changes were indicated by the changes of percentages of $\Delta \mathrm{T}(\Delta$ transmittance) of the adsorbent alumina without activation, acid activation, and base activation as $=61.2,41.8$, and $63.7 \%$, respectively. The $\Delta \mathrm{T}$ percentage of the total content of $\mathrm{O}-\mathrm{H}$ of the base activation alumina is higher than that of alumina without activation and acid activation. Acid-base activation in silica and alumina adsorbents can cause the change in the intensity of the vibration of $\mathrm{O}-\mathrm{H}$.

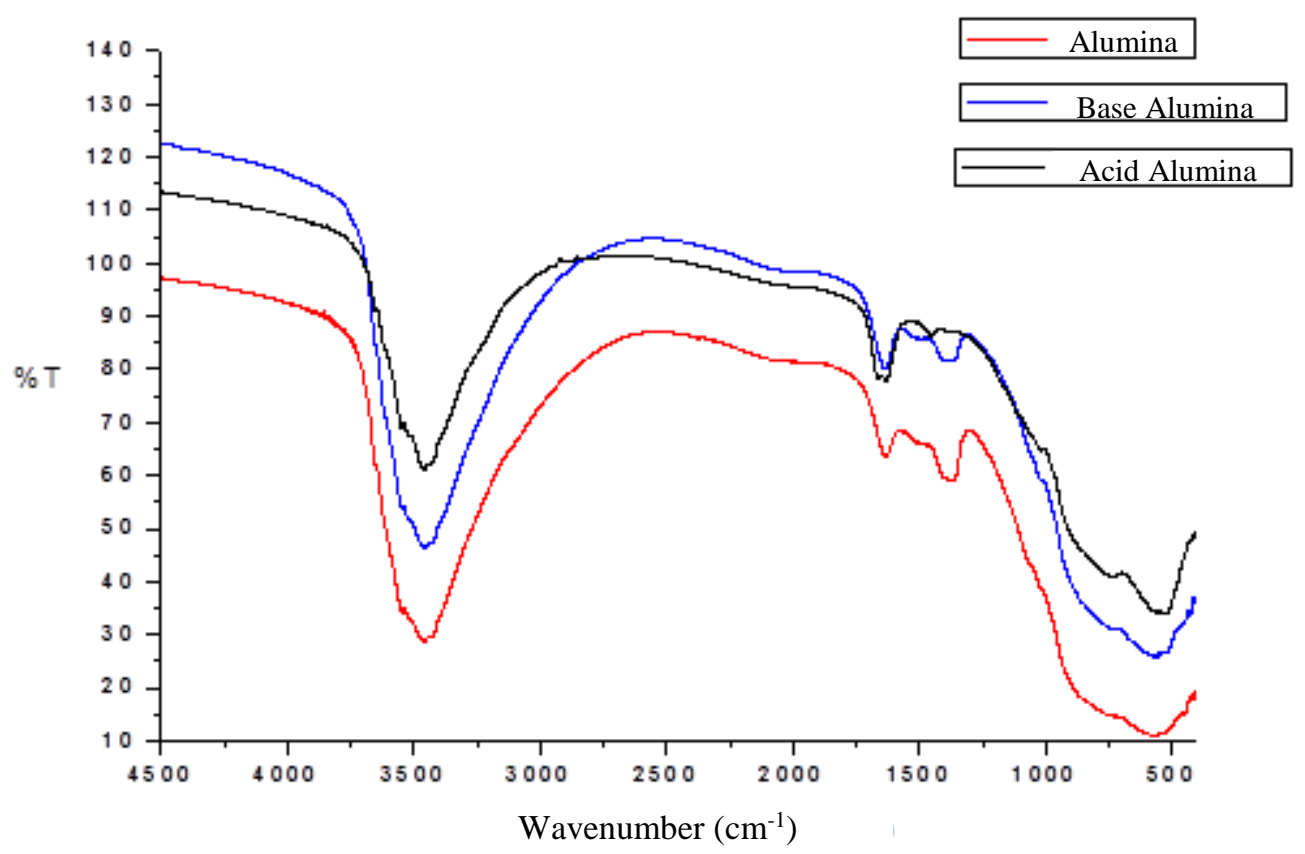

Figure 2. FTIR spectra of alumina adsorbents without activation, acid activated and base activated.

\section{Rhodamine B adsorption activity of silica and alumina adsorbents}

Adsorption of $10 \mathrm{ppm}$ Rhodamine B dye solution was conducted to determine the adsorption activity of the adsorbent silica and alumina to Rhodamine $\mathrm{B}$ dye. Various $\mathrm{pH}$ conditions of Rhodamine B also affect the adsorption activity of the adsorbent for the adsorbate. The $\mathrm{pH}$ conditions can form some structure of Rhodamine $\mathrm{B}$. At the low $\mathrm{pH}$ conditions $(\mathrm{pH} \leq 5)$ Rhodamine B tends to form the cationic structure that positively charged 
on $=\mathrm{N}^{+}(\mathrm{Et})_{2}$ group. At high $\mathrm{pH}$ conditions $(\mathrm{pH} \geq 6)$, Rhodamine $\mathrm{B}$ tends to form a zwitter ionic structure (Motahari et al., 2014).

\section{Rhodamine B adsorption}

Figure 3 shows the optimum adsorption activity of Rhodamine B to the acidactivated silica is $97.15 \pm 0.113 \%$. The active site of silica (silanol) have more $\mathrm{H}^{+}$ions from the acid solution so can reacted with Rhodamine B which have negative charge (-COO*) form zwitter ionic structure. However, the interaction between Rhodamine B with silica is more likely through a cation exchange mechanism in chemisorption (Long et al., 2016).

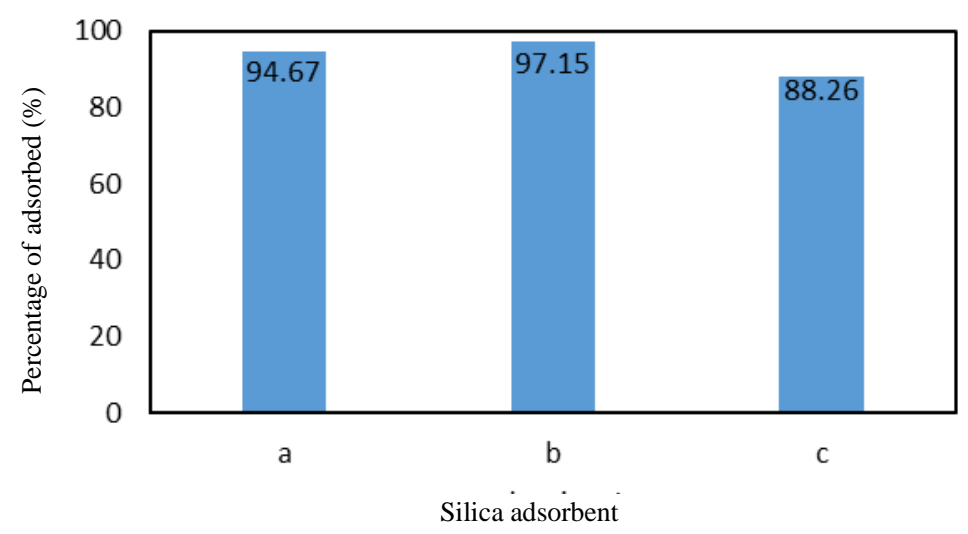

Figure 3. Decreasing the concentration of Rhodamine B dye after going through the process of adsorption using silica adsorbent (a) without activation, (b) acid activated, and (c) base activated.

No significant difference on Rhodamine B dye adsorption activity to un-activated alumina and acid-, and base- activated adsorbent was observed. This is consistent with the results of FTIR spectra of the activated alumina and without activation showed the amount of $\mathrm{O}-\mathrm{H}$ did not differ significantly. The optimum activity of base- activated alumina to adsorb Rhodamine B was $86.86 \pm 0.371 \%$ as shown in Figure 4 .

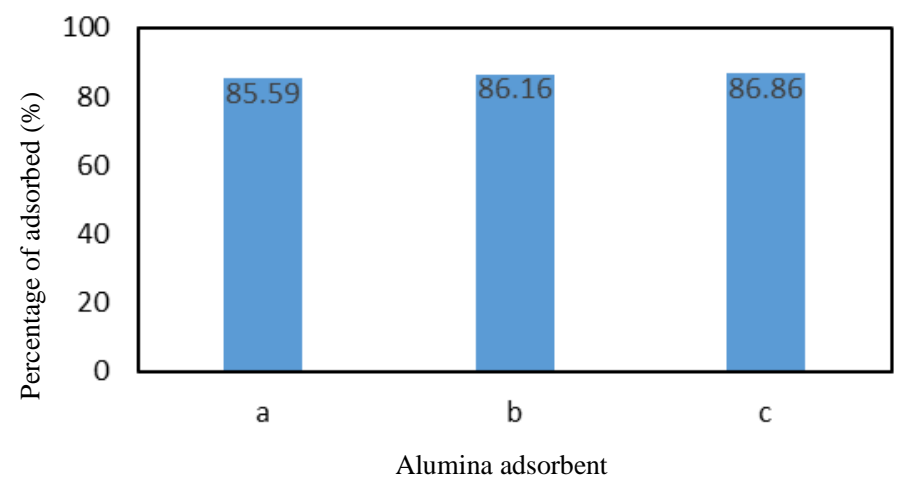

Figure 4. Decreasing the concentration of Rhodamine B dye after going through the process of adsorption using alumina adsorbent (a) without activation, (b) acid activated, and (c) base activated. 


\section{Rhodamine B adsorption at various $\mathrm{pH}$ conditions using acid and base activated silica.}

Figure 5 shows the optimum Rhodamine B dye adsorption using an acid-activated silica at $\mathrm{pH} 9$ reached $83.35 \pm 0.408 \%$, which in these conditions Rhodamine B dye tends to form structures zwitter ion (Motahari et al., 2014) which has a negative charge thus the interaction with silica is much more powerful than the acidic form's Rhodamine B structure while in acidic conditions it forms cationic structure. In contrast, at the highly acidic conditions ( $\mathrm{pH}$ 2), Rhodamine B was adsorbed up to $81.91 \pm 8.175 \%$ using base activated silica adsorbents. Interaction of cationic form of Rhodamine B and base activated silica that has more dominant $\mathrm{O}-\mathrm{H}$ group in the silanol active site provides an effective role to quarantine the Rhodamine B molecule.

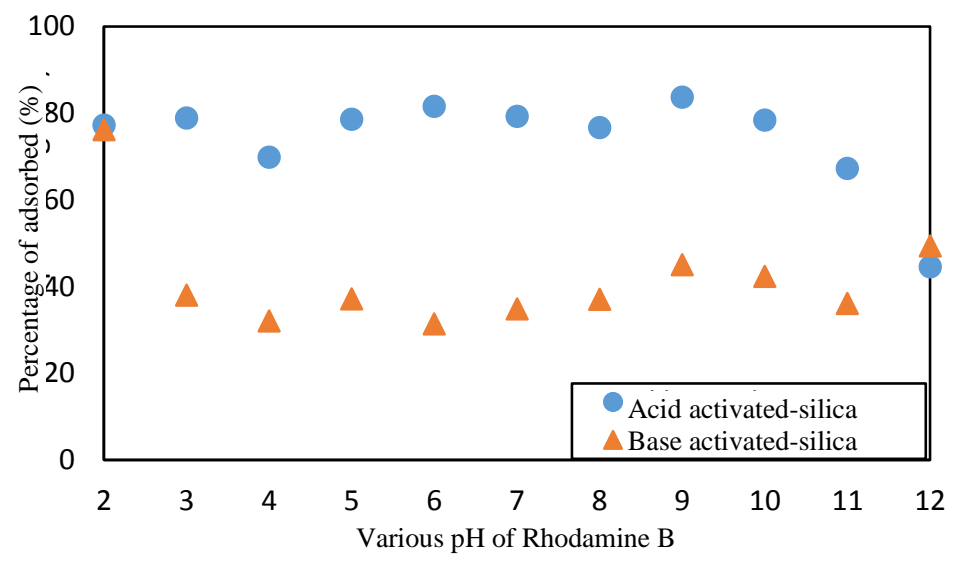

Figure 5. The percentage of adsorption at a various $\mathrm{pH}$ with acid- and base-activated silica as adsorbent.

\section{Rhodamine B adsorption at various pH conditions using acid and base activated alumina.}

The optimum of Rhodamine B adsorption activity using an acid-activated alumina at pH 8 was $74.73 \pm 10.109 \%$ as shown in Figure 6 . It is due to the structure of Rhodamine B in the base condition can form zwitter ionic which interacted with active groups of acidactivated alumina. The adsorption activity of base-activated alumina has similar to the adsorption activity of base-activated silica adsorbent, where in $\mathrm{pH} 2$ the Rhodamine $\mathrm{B}$ (cationic structure) adsorption activity with base-activated silica adsorbent was $69.20 \% \pm$ 21.285. The interaction of adsorbent and Rhodamine B can form cationic and zwitter ion because of several bonds, such as hydrogen bonds, ionic bonds, or cation exchange interactions of adsorbents with Rhodamine B (Jain et al., 2007). 


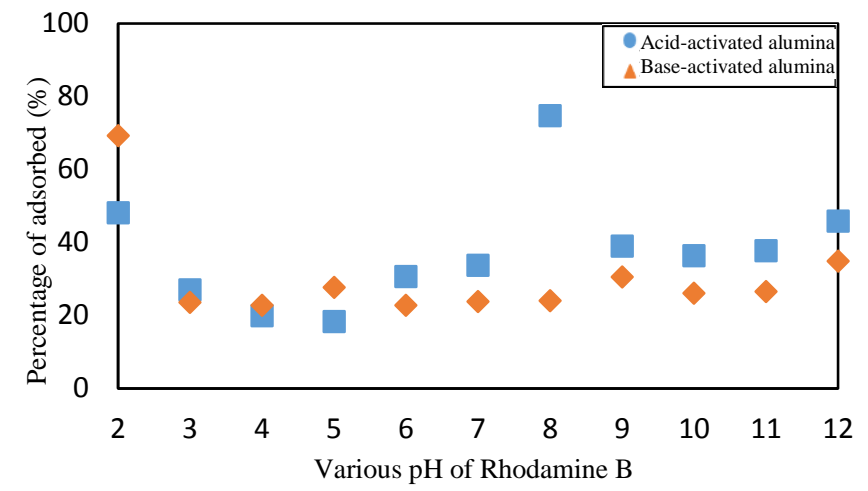

Figure 6. The percentage of adsorption at a various $\mathrm{pH}$ of Rhodamine B solution.

\section{Characterization of $\mathrm{Ti} / \mathrm{TiO}_{2}$ and $\mathrm{Ti} / \mathrm{TiO}_{2}-\mathrm{NiO}$ electrode}

The electrode of $\mathrm{Ti} / \mathrm{TiO}_{2}$ was prepared by coating $\mathrm{TiO}_{2}$ on plate of titanium. The diffractogram of $\mathrm{Ti} / \mathrm{TiO}_{2}$ is shown in Figure 7, which all peaks are belong to the characteristic of crystalline $\mathrm{TiO}_{2}$ (anatase). The peaks appears in the $2 \theta=25^{\circ}\left(\mathrm{d}_{101}=3.4967\right.$ $\AA), 2 \theta=37^{\circ}\left(\mathrm{d}_{004}=2.3679 \AA\right), 2 \theta=48^{\circ}\left(\mathrm{d}_{200}=1.8874 \AA\right), 2 \theta=54^{\circ}\left(\mathrm{d}_{105}=1.6931 \AA\right)$, and $2 \theta$ $=62^{\circ}\left(\mathrm{d}_{211}=1.6674 \AA\right)$ according to the JCPDS standard No. $78-2486$.

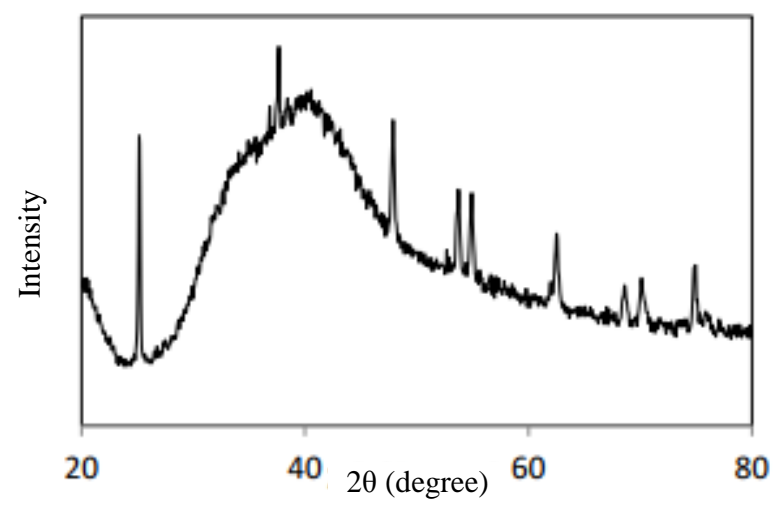

Figure 7. Diffractogram of $\mathrm{Ti} / \mathrm{TiO}_{2}$ electrode.

The diffractogram of $\mathrm{Ti} / \mathrm{TiO}_{2}-\mathrm{NiO}$ electrode shown in Figure 8 presents the peaks of $\mathrm{TiO}_{2}-\mathrm{NiO}$ composite at $2 \theta=25^{\circ}\left(\mathrm{d}_{012}=3.4768 \AA\right), 2 \theta=27^{\circ}\left(\mathrm{d}_{110}=2.340 \AA\right), 2 \theta=38^{\circ}\left(\mathrm{d}_{110}=\right.$ $2.3540 \AA), 2 \theta=40^{\circ}\left(\mathrm{d}_{102}=2.2441 \AA\right), 2 \theta=54^{\circ}\left(\mathrm{d}_{018}=1.6895 \AA\right)$, and $2 \theta=70^{\circ}\left(\mathrm{d}_{103}=1.3330\right.$ $\AA$ ) according to the JCPDS standard No. 33-0960. 


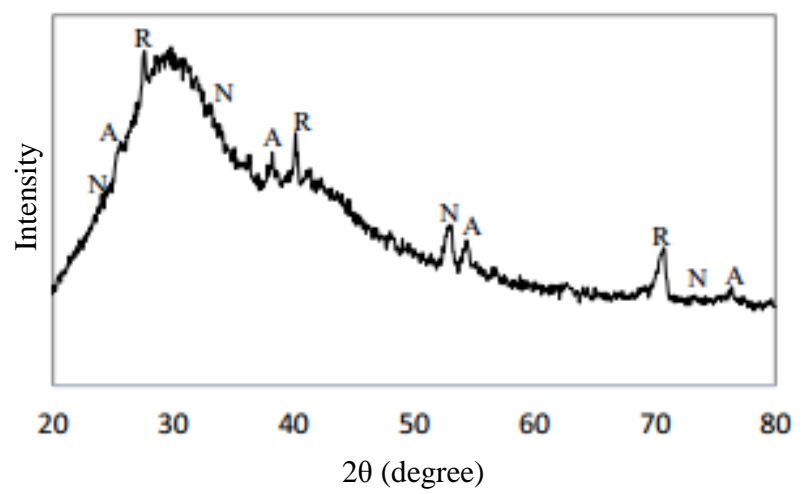

Figure 8. The diffractogram of $\mathrm{Ti} / \mathrm{TiO}_{2}-\mathrm{NiO}$ electrode $\left(\mathrm{N}=\mathrm{NiTiO}_{3} ; \mathrm{A}=\mathrm{TiO}_{2}\right.$ (anatase); $\mathrm{R}=\mathrm{TiO}_{2}$ (rutile)).

\section{Photoelectrocatalityc degradation of Rhodamine B}

The photoelectrodegradation process was also studied to optimize the concentration decrease of Rhodamine B. The degradation of $10 \mathrm{ppm}$ Rhodamine B was done by a photoelectrocatalityc reactor in the batch system using 300 Watt halogen lamp as a source of photon energy. The voltage applied to a working electrode was set at 6 volts using a potentiostat. The measurements were made using a single electrode system where $\mathrm{Ti} / \mathrm{TiO}_{2}-$ $\mathrm{NiO}$ and $\mathrm{Ti} / \mathrm{TiO}_{2}$ were used as photoanode a photocathode, respectively.

The experimental measurements were performed on $10 \mathrm{ppm}$ Rhodamine B dye in various $\mathrm{pH}$ conditions. The $\mathrm{pH}$ conditions applied were derived from optimum $\mathrm{pH}$ conditions obtained in the adsorption studies using various types of adsorbents at the $\mathrm{pH}$ conditions of 2, 8 , and 9 and a neutral $\mathrm{pH}$. Figure 9 shows the optimum photoelectrodegradation activity under acidic conditions ( $\mathrm{pH} 2$ ) of Rhodamine B of $90.76 \pm 0.046 \%$. This is because of the cationic structure of Rhodamine $\mathrm{B}$ able to interact with radical $\mathrm{OH}^{*}$ and $\mathrm{O}_{2}{ }^{\bullet}$ that formed by photoanode. The form of zwitterionic structure of Rhodamine B less degraded than the cationic form (Wahyuningsih et al., 2013).

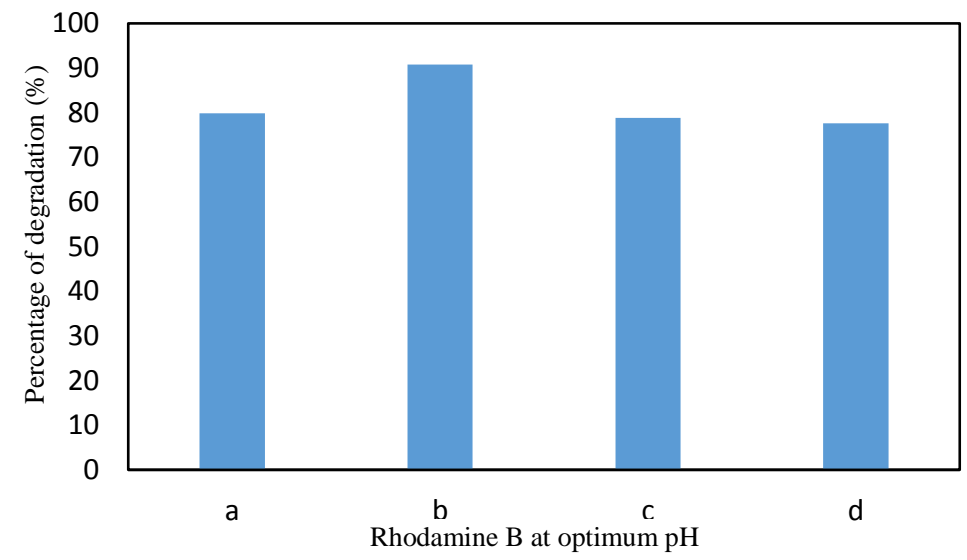

Figure 9. The percentage of degradation after photoelectrodegradation at (a) a neutral $\mathrm{pH}$, (b) $\mathrm{pH}=2$, (c) $\mathrm{pH}=8$, and (d) $\mathrm{pH}=9$. 


\section{Combined Systems of Adsorption and Photoelectrodegradation to Optimized-the concentration decrease of Rhodamine B}

The results of adsorption and photoelectrodegradation systems can be combined in order to know the value of concentration decrease of Rhodamine B after both processes. Figure 10 shows the optimum combined system of adsorption and photoelectrodegradation system reached at $98.79 \%$ concentration decrease of Rhodamine B using base activated silica and Rhodamine B pH condition at highly acid ( $\mathrm{pH} 2)$.

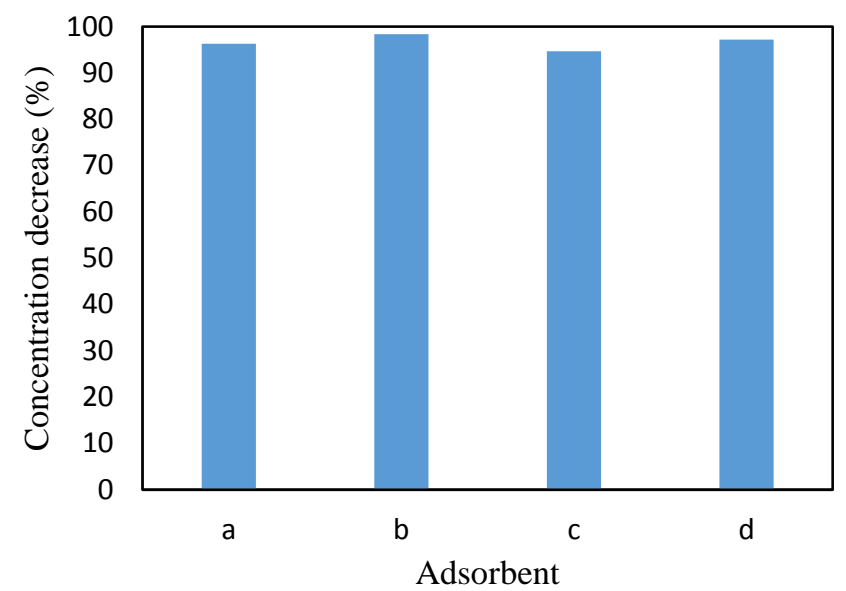

Figure 10. Decreasing of Rhodamine $B$ concentration after treatment in the combination of adsorption and photoelectrodegradation using adsorbent (a) silica acid, (b) silica base, (c) alumina acid, and (d) alumina base.

The percentage of degraded Rhodamine $\mathrm{B}$ has an average increase which equals to $12.11 \pm 6.04 \%$ after the adsorption process using an adsorbent of acid- and base-activated silica and acid- and base-activated alumina. This increase shows that the degradation of Rhodamine B using a combination of adsorption and photoelectrodegradation systems provided a better result than using a photoelectrodegradation systems only.

\section{CONCLUSIONS}

The acid and base activation to silica and alumina adsorbent changed the total amount of $-\mathrm{OH}$ group in the adsorbent. The optimum adsorption reached when the acid-activated adsorbent adsorb Rhodamine B under base condition, due to the formation of zwitter ionic structure. Meanwhile, base-activated adsorbent has an optimum adsorption activity when Rhodamine B in a highly acid condition that formed cationic structure. Adsorption and photoelectrodegradation combination system using photoanode $\mathrm{Ti} / \mathrm{TiO}_{2}-\mathrm{NiO}$ at a bias potential of $6 \mathrm{~V}$ cause a decrease of Rhodamine B dye concentration of $98.79 \%$ using baseactivated silica at highly acid $\mathrm{pH}$ condition $(\mathrm{pH} 2)$. 


\section{REFERENCES}

Alver, E., Metin, A. U., 2012. Anionic Dye Removal from Aqueous Solutions Using Modified Zeolite: Adsorption Kinetics and Isotherm Studies. Chemical Engineering Journal 200-202, 59-67.

Al-Ghouti, M.A., Khraisheh, M.A.M., Allen, S.J., Ahmad, M.N., 2003. The Removal of Dyes from Textile Wastewater: A Study of The Physical Characteristics and Adsorption Mechanisms of Diatomaceous Earth. Journal of Environmental Management 69 (3), 229-238.

Gunlazuardi, J., 2001. Fotokatalisis pada Permukaan TiO 2 : Aspek Fundamental dan Aplikasinya. Seminar Nasional Kimia Fisika II. Universitas Indonesia, Jakarta

Huang, C.H., Chang, K.P., Ou, H.D., Chiang, Y.C., Wang, C.F., 2011. Adsorption of Cationic Dyes onto Mesoporous Silica. Microporous and Mesoporous Materials 141, 102-109.

Jain, R., Mathur, M., Sikarwar, S., Mittal, A., 2007. Removal of The Hazardous Dye Rhodamine B Through Photocatalytic and Adsorption Treatments. Journal of Environmental Management 85, 956-964.

Kannan, C., Sundaram, T., Palvannan, T., 2008. The Environmentally Stable Adsorbent of Tetrahedral Silica and Non-Tetrahedral Alumina for Removal and Recovery of Malachite Green Dye from Aqueous Solution. Journal of Hazardous Materials 157, 137-145.

Long, Z., Xu, W., Lu, Y., Qiu, H., 2016. Nanosilica-Based Molecularly Imprinted Polymer Nanoshell for Specific Recognition and Determination of Rhodamine B in Red Wine and Beverages. Journal of Chromatography. B, Analytical Technologies in The Biomedical and Life Sciences 1029-1030, 230-238.

Mahmoud, M.E., Osman, M.M., Hafez, O.F., Hegazi, A.H., Elmelegy, E., 2010. Removal and Preconcentration of Lead (II) and Other Heavy Metals from Water by Alumina Adsorbents Developed by Surface-Adsorbed-Dithizone. Desalination 251 (1-3), 123-130.

Malakootian, M., Mansoorian, H.J., Hosseini, A., Khanjani, N., 2015. Evaluating The Efficacy of Alumina/Carbon Nanotube Hybrid Adsorbents in Removing Azo Reactive Red 198 and Blue 19 Dyes from Aqueous Solutions. Process Safety and Environmental Protection 96, 125-137.

Motahari, F., Mozdianfard, M.R., Salavati-Niasari, M., 2014. Synthesis and Adsorption Studies of $\mathrm{NiO}$ Nanoparticles in Presence of $\mathrm{H}_{2}$ acacen Ligand for Removing Rhodamine B in Wastewater Treatment. Process Safety and Environment Protection 93, 282-292.

Silverstein, R.M, Bassler, G.C, Morril, T.C., 1991. Spectrometric Identification of Organic Compounds $4^{\text {th }}$ Edition. John Wiley and Sons Inc., New York.

Sen, S., and Demirer, G. N., 2003. Anaerobic Treatment of Real Textile Wastewater with A Fluidized Bed Reactor. Water Research 37, 1868-1878.

Sun, D., Zhang, Z., Wang, M., Wu, Y., 2013, Adsorption of Reactive Dyes on Activated Carbon Developed from Enteromorpha prolifera. American. Journal of Analytical Chemistry 4, 17-26. 
Wahyuningsih, S., Purnawan, C., Kartikasari, P.A., Praistia, N., 2013. Visible Light Photoelectrocatalytic Degradation of Rhodamine B Using A Dye-Sensitized $\mathrm{TiO}_{2}$ Electrode. Chemical Paper 68(9), 1248-1256.

Wahyuningsih, S., Purnawan, C., Saraswati, T. E., Pramono, E., Ramelan, A. H., Pramono, S., Wisnugroho, A., 2014. Visible Light Photoelectrocatalytic Degradation of Rhodamine B Using $\mathrm{Ti} / \mathrm{TiO}_{2}-\mathrm{NiO}$ Photoanode. Journal of Environmental Protection $5,1630-1640$. 